\title{
¿Por qué existe una alta tasa de mortalidad y letalidad por la COVID-19 en el Perú y la región Lambayeque?
}

\section{Why is there a high rate of mortality and fatality of COVID-19 in Peru and the region of Lambayeque?}

\author{
Víctor Soto-Cáceres ${ }^{1, a}$
}

\section{Sr. Editor:}

A nivel mundial se presenta la pandemia COVID-19 y al 23 de setiembre de 2020, fecha de redacción de este artículo, el número de casos confirmados asciende a 31375325 y 966399 fallecimientos por esta enfermedad. El Perú figura en quinto lugar mundial de incidencia con 772896 casos ${ }^{(1)}$.

Lamentablemente el Perú también registra 31474 fallecidos, y considerando que la población estimada para el 2020, según el Instituto Nacional de Estadística e Informática (INEI), es de 32625948 habitantes (2), tenemos la más alta tasa de mortalidad en el mundo de 98,68 x 100000 habitantes y una alta tasa de letalidad de 4,1 por 100 casos ocupando el cuarto lugar mundial ${ }^{(3)}$.

En la región Lambayeque, según el reporte oficial al 22 de setiembre, las cifras ascienden a 25229 casos y 1970 defunciones (4), cuya tasa de letalidad es de 7,81 por 100 casos, casi el doble del nivel nacional a pesar de haber disminuido la tasa de letalidad que en el mes de mayo era de $10 \%{ }^{(5)}$.

En base a la población oficialmente estimada de Lambayeque que es 1310785 habitantes ${ }^{(6)}$, la tasa de mortalidad por la COVID-19 es de 150,29 por 100000 habitantes mucho mayor que en todo el país.

Entonces se requiere revisar esta grave situación de alta mortalidad y letalidad en el Perú y Lambayeque, por lo que se considera oportuno intentar algunas explicaciones como las siguientes:

1) Descuido total del primer nivel de atención. Toda epidemia siempre ha sido atendida primero, como debe ser, en el primer nivel de atención, las postas y centros de salud para el diagnóstico y tratamiento inmediato, intentando evitar el progreso a complicaciones o que el paciente tenga que acudir al hospital. A nivel regional se cerraron los establecimientos del primer nivel y se actuó a la inversa: se priorizó el tercer nivel, es decir, los hospitales, las unidades de cuidados intensivos, que con el descuido y colapso del sistema de salud que ya existía fueron insuficientes para la atención de pacientes que llegaban graves y cuya gran mayoría en $80 \%$ fallecían en $\mathrm{UCl}$ o a las 24 horas de ingresar al hospital, sumado a esto las colas y estancias inadecuadas por falta de camas.

2) Inexistencia de pruebas diagnósticas adecuadas. No se contaba con prueba molecular PCR para diagnosticar los nuevos casos positivos y aislarlos con el fin de evitar su difusión; se compraron pruebas rápidas que sirven para determinar la prevalencia, esto es el total de casos, no siendo la mayoría de ellos nuevos a lo que se sumaban los falsos negativos.

3) Inadecuada actitud del gobierno al decretar la cuarentena prolongada obligatoria. Esta medida pudo ser efectiva por dos semanas o un mes, pero no por cinco meses, pues más del $70 \%$ de la población económicamente activa es informal, con ingresos diarios precarios, por lo que no podían quedarse en su casa a morir de hambre; además, una buena parte de la población no dispone de agua corriente para lavarse las manos y vive en forma hacinada, lo cual les dificultada cumplir con el distanciamiento social intradomiciliario.

\footnotetext{
1. Universidad Nacional Pedro Ruiz Gallo. Facultad de Medicina Humana, Lambayeque, Perú

a. Médico especialista en medicina interna y epidemiología. Doctor en Medicina.
}

ORCID: https://orcid.org/0000-0003-2030-0951 
4) Entrega de bonos económicos. Esos bonos se hizo entrega a una población que no tiene cuenta bancaria ni dispone de internet domiciliario ni sabe manejarlo para saber si ha sido favorecida o no, pues menos del $40 \%$ de peruanos contaba con cuenta bancaria, según el Ministerio de Economía, obligando de este modo a la existencia diaria de largas colas en todos los bancos y por varios meses, sin distanciamiento social, aumentando aún más los contagios.

5) Incorrecto manejo de los mercados. No se dispuso la apertura de pequeños mercados adicionales y mercados rodantes. La población seguía acudiendo a los grandes mercados populares donde era imposible establecer el distanciamiento social ni lograr la previa desinfección con alcohol gel en las manos como sí sucedía en los supermercados y en los minimarkets que se abrieron posteriormente, pero no por iniciativa de las autoridades.

6) Incumplimiento general de la población respecto a las restricciones impuestas. Se ha incumplido la inmovilización social en domicilio, el distanciamiento social prolongado, las medidas que pudieron ser útiles en poblaciones muy diferentes como las europeas pero que no eran factible de aplicarlas en nuestro medio.

7) Escasez de oxígeno medicinal. A pesar de que se sabía que la pandemia iba a significar el incremento de contagios, la mayoría leves o moderados, pero con un $10 \%$ graves, y que lo principal que se necesitaría era oxígeno, este no existía en cantidad suficiente en los hospitales ni de manera particular para conseguirlo, debido trabas burocráticas. En un principio por establecer que fuera $97 \%$ siendo suficiente disponer de 93 o 95 \% (7) lo que limitó su disponibilidad, y luego por no aceptar, por aspectos políticos, el apoyo de grandes empresas para utilizar dicho oxígeno, así como no haber gestionado su adquisición oportuna.

Conflictos de interés: El autor declara no tener conflicto de interés en esta publicación.

Fuentes de inanciamiento: Autofinanciado

\section{REFERENCIAS BIBLIOGRÁFICAS}

1. World Healtn Organization. WHO Coronavirus Desease (COVID 19) Dashboard Data last updated: 2020/9/23, 12:21pm CEST available in: https://covid19. who.int/?gclid=CjwKCAjw5Kv7BRBSEiwAXGDEIWB9iL4KmFpegewM33xbksYmyX9O0S0-8xfZrrT_jsUXcQh1zmSemRoCZLYQAvD_BwE

2. Instituto Nacional de Estadística e Informática. La población de Lima supera los nueve millones y medio de habitantes. Disponible en: http://m.inei.gob.pe/prensa/noticias/la-poblacion-de-lima-supera-los-nueve-millones-y-medio-de-habitantes-12031/

3. Jhon Hopkins. Coronavirus resource center. Cases and mortality by country. 2020/9/23 Available: https://coronavirus.jhu.edu/data/mortality
4. Gerencia Regional de Salud Lambayeque. Reporte COVID19. Situación al 22 de setiembre 2020 a las 12.00 horas. Disponible en: https://www.facebook.com/GERESALAMB/

5. Gerencia Regional de Salud Lambayeque. Reporte COVID19. Situación al 22 de junio 2020 a las 12.00 horas. Disponible en: https://www.facebook. com/GERESALAMB/

6. Ministerio de Salud. Estadística poblacional. Lambayeque estimada 2020. Disponible

7. https://www.minsa.gob.pe/reunis/data/poblacion_estimada.asp

8. Defensoría del Pueblo. Crisis de oxígeno para pacientes de covid19: alternativas de solución. Serie Informes Especiales N 017-2020-DP Disponible en: https://www.defensoria.gob.pe/wp-content/uploads/2020/06/Serie-Informes-Especiales-N\%C2\%BA-017-2020-DP.pdf 